\title{
Immunisation timeliness in a cohort of urban Aboriginal and Torres Strait Islander children
}

\author{
Yolanda G. Lovie-Toon ${ }^{1 *}$, Kerry K. Hall ${ }^{1}$, Anne B. Chang ${ }^{1,2,3}$, Jennie Anderson ${ }^{4}$ and Kerry-Ann F. O'Grady ${ }^{1}$
}

\begin{abstract}
Background: To evaluate immunisation coverage, timeliness and predictors of delayed receipt in urban Australian Indigenous children during the first 18 months of life.

Methods: Cross-sectional retrospective analysis of data collected from 140 Australian Indigenous children aged < 5 years at the time of enrolment in a prospective cohort study on respiratory illness between 14 February 2013 and 28 January 2015. Children were recruited through an urban community primary health care centre in the Northern suburbs of Brisbane, Queensland.

Results: The proportion of children with completed immunisation schedules was 50 of 105 (47.6\%) at 7 months, 30 of $85(35.3 \%)$ at 13 months and 12 of $65(18.5 \%)$ at 19 months. Timely receipt of diphtheria-tetanus-pertussis decreased from $78.4 \%$ at 2 months of age to 63.7 and $59.3 \%$ at 4 and 6 months respectively. Amongst the 105 parents/guardians with children $\geq 7$ months at enrolment, 71 (67.6\%) incorrectly reported their child's immunisation status. Delayed vaccine receipt was significantly associated ( $p \leq 0.05$ ) with having multiple children in the household, mother's unemployment and premature birth.

Conclusions: Coverage and timeliness among this population is suboptimal and decreases as children age. Parent/ guardian reporting of vaccination status was unreliable. Children of unemployed mothers and those with multiple siblings should be targeted to improve community immunisation timeliness due to a greater risk of vaccination delay. High quality trials, conducted in several settings to account for the diversity of Australian Indigenous communities are urgently needed to identify culturally appropriate, effective and sustainable strategies to improve immunisation targets in children.
\end{abstract}

Keywords: Indigenous, Aboriginal, Australia, Childhood, Paediatrics, Immunisation, Timeliness

\section{Background}

Vaccine timeliness, important for early individual protection and generation of herd immunity [1], is particularly crucial in infancy [2] and settings with high infection rates (e.g. Indigenous communities). Australian Indigenous Australian children experience higher notification and hospitalisation rates for vaccine preventable infections and diseases than non-Indigenous children [3-6]. Furthermore, some infections pose a greater risk of severe disease and

\footnotetext{
*Correspondence: y.lovietoon@qut.edu.au

${ }^{1}$ Institute of Health \& Biomedical Innovation, Queensland University of Technology, Centre for Children's Health Research, South Brisbane, QLD, Australia

Full list of author information is available at the end of the article
}

adverse outcomes when contracted during infancy and early childhood [3].

In 2013, national vaccination coverage at 12,24 and 60-months was $86.0,92.0$ and $93.0 \%$ respectively among Indigenous children, and 90.6, 92.1 and 91.6\% among non-Indigenous children [5]. Although these are applauded, reporting coverage at these milestones can conceal overdue vaccination occurring before these milestones $[7,8]$ and data reported at a national level does not account for the heterogeneity of Australian Indigenous communities. A number of Australian studies have now highlighted the gap in timely immunisation between Indigenous and non-Indigenous children, including regional differences, 
over the past decade $[4,7,9,10]$. The most current data indicates that the gap in timeliness remains, with the proportion of delayed receipt being 5.8-21.6 percentage points higher among Indigenous children compared to non-Indigenous children for selected vaccines (3rd dose of diphtheria-tetanus-pertussis (DTP) and 1st and 2nd dose of measles-mumps-rubella (MMR) [5]. However there are limited current data on whether this gap exists among other vaccines and at earlier time points. There are also little data on differences in coverage within and between Indigenous communities and on predictors of incomplete coverage and timeliness in this population that account for its diversity. Availability of such data would inform a targeted approach and potentially influence policy in our era of limited health resources.

Our primary objective was to evaluate vaccination coverage and timeliness during the first 18-months of life among a cohort of urban Indigenous children. Our secondary objectives were to: a) identify potential predictors of delayed vaccination, and; b) evaluate the validity of parent/carer report of child immunisation status.

\section{Methods}

This study was conducted in an urban community primary health care centre in the Northern suburbs of Brisbane, Queensland. The centre opened in 2011 and has over 10,000 registered clients. Approximately 65\% identify as Aboriginal and/or Torres Strait Islander, which approximates to $14 \%$ of the Brisbane's Indigenous population based on the most recent census data [11].

This paper reports on results from a retrospective analysis of children at the time of enrolment into a prospective cohort study of paediatric acute respiratory illnesses (ARI) currently underway at the centre [12]. Children presenting to the centre for any reason, including accompanying another person, are invited to participate. Children are eligible for participation if they are aged $<5$ years at time of enrolment, registered as a patient with the clinic and intend to remain in the study area for the following 12 months. Written consent is obtained from the parent(s)/guardian(s) before study entry. Ethical approval was obtained from the Queensland Children's Health Services (HREC/12/QRCH/169) and the Queensland University of Technology (1300000741) Human Research Ethics Committees. Additionally, this study was conducted in accordance with the guidelines for ethical conduct in Aboriginal and Torres Strait Islander Health Research outlined by the Australian National Health and Medical Research Council [13] and the cultural oversight was provided by an Indigenous Reference Group. Indigenous children enrolled prior to 28 January 2015 were included in this analysis. As per national standards, Indigenous status was determined through self-report [14]. Of all the children aged $<5$ years registered in the clinic during the study period, $16.3 \%$ participated in this study.

Parent/guardian-reported demographic, infant, maternal and paternal characteristics were collected at baseline. Parent/guardian report of their child's immunisation status was collected by asking "Is your child age appropriately immunised for childhood vaccines?". With parent/ guardian consent, immunisation records were retrieved from the Australian Childhood Immunisation Register (ACIR). ACIR is a nationwide opt-out register characterised by incentivised reporting of vaccine administration by immunisation providers. Inclusion in ACIR is based on one's enrolment in Australia's universal health care scheme, of which $99 \%$ of Australians are enrolled in by 12 months of age [5].

During the period in which the study participants were born (2008-2014), there were multiple changes to the Immunisation Program Schedule for Queensland [15]. Therefore our analysis was conducted according to antigens, opposed to vaccines. Only those antigens that were recommended for Indigenous children at the same time points across all five schedules (Table 1) were included in our analysis. The series of vaccines due at 2, 4 and 6 months are henceforth referred to as the primary series' of vaccines.

In Queensland, the majority of vaccines administered to infants and young children are administered by general practitioners through primary health care centres. Some local government areas also provide public immunisation clinics. Vaccines given at birth (e.g. Bacillus CalmetteGuérin) are routinely received through hospitals and frequently recorded in a different system to ACIR. Therefore birth vaccines were excluded from all analyses.

Immunisation coverage and timeliness was calculated using only those vaccines received prior to or on the date of enrolment. Children were included in the coverage and timeliness calculations at each milestone if, at

Table 1 Antigens recommended for Indigenous children across all QLD Immunisation Program Schedules used from 2008-2015

\begin{tabular}{ll}
\hline Age vaccine is due & Antigen \\
\hline $2,4 \& 6$ months & Diphtheria, Tetanus, Pertussis (DTP) \\
& Polio \\
& Hepatitis B (HepB) \\
& Haemophilus influenza type b (Hib) \\
& Rotavirus (Rota) \\
& Pneumococcal (PCV) \\
& Measles, mumps, rubella (MMR) \\
& Haemophilus influenza type b (Hib) \\
& Meningococcal C (MenC) \\
& Varicella \\
& Hepatitis A (HepA) \\
\hline
\end{tabular}


their date of enrolment, they were $\geq 1$ month older than the respective milestone. This allowed for vaccines administered within 1 month of the vaccine due date to be included in the analyses.

The Australian National Centre for Immunisation Research and Surveillance routinely allows a 3-month lag period between vaccine receipt and report to ACIR [5]. Therefore, we only analysed vaccines that were due to have been received $\geq 3$ months prior to the date we extracted immunisation records from ACIR. Immunisation timeliness was classified according to the differences in weeks between the dates at which vaccines were due and actually received. There is no universally accepted definition of vaccine timeliness. Australian studies typically define timely receipt as received $\leq 30$ days after the vaccine due date and delayed as $>30$ days after the due date $[5,7,10]$. Therefore timeliness was classified using the following definitions:

a) Early (received $>14$ days before due date)

b) No delay (received between 14 days before and 30 days after due date)

c) Delayed (received $>30$ days after the due date)

d) Not received (no recorded dose prior to enrolment date)

e) Incorrectly received (vaccine received when not due/eligible)

The third dose assumption was not applied to the treatment of ACIR data in this study. This assumes that where there is a record of a second or third dose of a vaccine being received the previous dose has also been received, regardless of whether there is a record of it [16]. We assumed that the first record of any vaccination on ACIR was the first dose and checked the effect of that assumption by evaluating the number of children for whom a third dose assumption would have been applied if we had taken that approach.

\section{Statistical analysis}

Child characteristics at enrolment and vaccination data were tabulated and expressed as proportions and/or mean/medians with the corresponding 95\% Confidence Intervals (CI) or Interquartile Ranges (IQR). To identify potential predictors of vaccination delay, exploratory univariate analyses were performed with timeliness recoded as a dichotomous variable with 'delayed' or 'not received' being classified as 'delayed', and 'early' or 'no delay' being classified as 'no delay'. Children with responses of 'unknown', 'not applicable' or 'declined to answer' for any of the predictor variables were excluded from the analysis. The predictor variables 'participating health care service is usual provider' and 'multiple birth' were excluded from the analyses as more than $90 \%$ of participants reported the same response. The analysis of predictors of timeliness was only performed for the DTP vaccines, given its consistency in the primary series across all vaccine schedules. A two-tailed $p$-value of $<0.05$ was considered significant. All analyses were performed in Stata V13 (StataCorp, Texas, USA).

\section{Results}

Between 14 February 2013 and 28 January 2015, 140 children were enrolled; median age at enrolment of 18.3 months (IQR 6.9-32.0). ACIR records were unavailable for four participants who were excluded from further analyses. Of the remaining 136 children, 71 (50.7\%) were male. Child characteristics and that compared to national Aboriginal and Torres Strait Islander population (where data are available) are provided in Table 2.

Immunisation coverage at the selected milestones was low among all age groups, and decreased in older children (Table 3). To consider the effect of the upper age restriction of rotavirus vaccines on overall coverage, coverage was recalculated excluding this antigen. The increase in coverage through the exclusion of rotavirus was by less than 10 percentage points at each milestone.

Vaccine receipt and timeliness are presented in Table 4 for each antigen and dose. The highest proportions of non- receipt were for the rotavirus vaccine due at 4 (26.7\%) and 6-months (42.9\%) and the HepA vaccine due at 18 -months (23.1\%). Among the primary series of immunisations, the proportion of the cohort who had received each vaccine decreased at each milestone.

The proportion of children who received a vaccine earlier than recommended was $\leq 2 \%$ for most vaccines and $5.1 \%$ for the varicella vaccine at 18 -months (Table 4 ). Among those children who received the primary series, most (58.7-89.7\%) received them with no delay (Fig. 1); this was not the case at 12 and 18-months of age. MMR due at 12-months and HepA due at 18-months had the highest rates of delayed receipt (53.7 and $72.0 \%$ respectively). Interestingly, there were notable variations in the proportions of receipt and timely receipt among the three vaccines due at 12 months, and more pronounceably among the two vaccines due at 18 months. Rotavirus vaccinations at 2, 4 and 6-months had the lowest rates of delayed receipt $(9.3,20.5$ and $16.7 \%$ respectively). For those vaccines that were delayed, the median number of weeks delayed ranged from 1.4 to 19.2 weeks, with rotavirus vaccines having the shortest median delay and vaccines due at 18 months having the longest median delay. There were 6 instances where vaccinations were incorrectly received' either because the child was not due or was no longer eligible to receive the vaccine. The majority of these instances (4/6) were due to rotavirus being administered outside the recommended age cut-offs. 
Table 2 Demographic, infant, maternal and paternal characteristics of study population

\begin{tabular}{|c|c|c|}
\hline Characteristic & $\begin{array}{l}N=140 \\
n(\%)\end{array}$ & $\begin{array}{l}\text { National Indigenous } \\
\text { population (\%) }\end{array}$ \\
\hline \multicolumn{3}{|l|}{ Sex } \\
\hline Male & $71(50.7)$ & $50.9[27]$ \\
\hline Female & $69(49.3)$ & $49.1[27]$ \\
\hline \multicolumn{3}{|l|}{ Care type } \\
\hline Both parents & $80(57.1)$ & $54.7[28]$ \\
\hline Single parent & $51(36.4)$ & $45.3[28]$ \\
\hline Other ${ }^{a}$ & $8(5.7)$ & \\
\hline Missing & $1(0.7)$ & \\
\hline \multicolumn{3}{|l|}{ Primary carer } \\
\hline Mother & $115(82.1)$ & \\
\hline Other ${ }^{b}$ & $16(11.4)$ & \\
\hline Missing & $9(6.4)$ & \\
\hline \multicolumn{3}{|l|}{ Childcare $^{c}$} \\
\hline Yes & $35(25.0)$ & $21.7^{\mathrm{f}}[29]$ \\
\hline No & $104(74.3)$ & \\
\hline Missing & $1(0.7)$ & \\
\hline \multicolumn{3}{|c|}{ Study clinic is usual health care provider } \\
\hline Yes & $131(93.6)$ & N/A \\
\hline No & $0(0.0)$ & N/A \\
\hline Missing & $9(6.4)$ & N/A \\
\hline \multicolumn{3}{|l|}{ Educational level of father } \\
\hline Did not finish high school & $63(45.0)$ & $58.0^{9}[30]$ \\
\hline High school & $37(26.4)$ & $16.0^{9}[30]$ \\
\hline Post-school qualification ${ }^{d}$ & $16(11.4)$ & $25.9^{9}[30]$ \\
\hline Missing & $24(17.1)$ & \\
\hline \multicolumn{3}{|l|}{ Educational level of mother } \\
\hline Did not finish high school & $54(38.6)$ & \\
\hline High school & $66(47.1)$ & \\
\hline Post-school qualification ${ }^{d}$ & $16(11.4)$ & \\
\hline Missing & $4(0.3)$ & \\
\hline \multicolumn{3}{|l|}{ Employment status of father } \\
\hline Employed $^{e}$ & $60(42.9)$ & $49.7^{\mathrm{h}}[30]$ \\
\hline Unemployed & $57(40.7)$ & $50.3^{\mathrm{h}}[17]$ \\
\hline Missing & $23(16.4)$ & \\
\hline \multicolumn{3}{|l|}{ Employment status of mother } \\
\hline Employed $^{e}$ & $17(12.1)$ & $43.0^{\mathrm{h}}[30]$ \\
\hline Unemployed & $121(86.4)$ & $57.0^{h}[30]$ \\
\hline Missing & $2(1.4)$ & \\
\hline \multicolumn{3}{|l|}{ Income level } \\
\hline$<\$ 26000$ & $44(31.4)$ & $35.2^{\mathrm{i}}[31]$ \\
\hline$\$ 26000-<\$ 52000$ & $56(40.0)$ & $34.3^{i}[31]$ \\
\hline$\$ 52000-<\$ 78000$ & $23(16.4)$ & $8.9^{i}[31]$ \\
\hline$\geq \$ 78000$ & $11(7.9)$ & $4.0^{i}[31]$ \\
\hline
\end{tabular}

Table 2 Demographic, infant, maternal and paternal characteristics of study population (Continued)

\begin{tabular}{|c|c|c|}
\hline Missing & $6(4.3)$ & \\
\hline \multicolumn{3}{|l|}{ Multiple birth } \\
\hline Singleton & $134(95.7)$ & $98.5^{\mathrm{j}}[32]$ \\
\hline Multiple & $1(0.7)$ & $1.5^{\mathrm{j}}[32]$ \\
\hline \multirow[t]{2}{*}{ Missing } & $5(3.6)$ & \\
\hline & Mdn (IQR) & Mean/Mdn \\
\hline $\begin{array}{l}\text { Number of children in household } \\
(N=138)\end{array}$ & $2.0(3.0-1.0)$ & \\
\hline $\begin{array}{l}\text { Age of mother at birth of child } \\
\text { (in years) }(N=138)\end{array}$ & $24.0(29.0-20.0)$ & $25.2^{\mathrm{k}}[33]$ \\
\hline $\begin{array}{l}\text { Age of father at birth of child } \\
\text { (in years) }(\mathrm{N}=135)\end{array}$ & $26.0(33.0-23.0)$ & $27.9^{k}[33]$ \\
\hline $\begin{array}{l}\text { Gestational age (in weeks) } \\
(\mathrm{N}=137)\end{array}$ & $40.0(40.0-38.0)$ & $38.2^{\mathrm{m}}[33]$ \\
\hline Birth weight (in grams) $(N=137)$ & $\begin{array}{l}3200.0(3628.0- \\
2770.0)\end{array}$ & $3200^{m}$ [33] \\
\hline
\end{tabular}

${ }^{\mathrm{a} O t h e r}=$ shared, other relative, other non-family member (including government care); ${ }^{\mathrm{b} O t h e r}=$ Father, Mother and Father, Grandparent, Grandparent and Father, Other non-family; ${ }^{C}$ Childcare $=$ formal regulated daytime care provided in a group setting, includes private or community centres and family day care; ${ }^{\mathrm{d}}$ Post-school qualification = Certificate, Diploma, Bachelor Degree; ${ }^{\mathrm{e}}$ Employed $=$ Full Time, Part

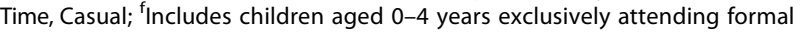
childcare and children aged 0-4 years attending both formal and informal childcare; ${ }^{9}$ Data represents both males and females; ${ }^{\text {h}}$ Unemployed $=$ those not participating in the labour force and those participating in the labour force but without work; 'Categories of income levels presented for national data differ from categories used in study and are as follows: $<\$ 20800$, $\$ 20800-<\$ 52000, \$ 52000-<\$ 78000, \geq \$ 78000 ;$ ' Data represents all Australian women, not solely Indigenous Australian women; ${ }^{\mathrm{k}}$ Median value; ${ }^{\mathrm{m}}$ Mean value

The majority of parents/guardians with children aged $\geq 7$-months at enrolment reported that their child was up-to-date $(96 / 105,91.4 \%)$. However parent/guardian report was not consistent with ACIR; $71.9 \%$ of parents/guardians with who considered their child was upto-date were incorrect compared to ACIR. Sensitivity and specificity of parental report was 93.1 and 9.2\% respectively.

Univariate unadjusted analyses of the associations between child characteristics and delayed receipt of DTP at 2, 4 and 6-months, as well as delayed receipt at any time point, are presented in Table 5 . There was a significant association $(p<0.05)$ between delayed receipt and the mother being unemployed at any time point (OR 6.6, $95 \%$ CI 1.37, 63.51). Delayed receipt was also significantly associated with having other children in the household at any time point, compared to no other children (1-2 other children OR 4.54, 95\% CI 1.52-13.55, $\geq 3$ other children OR $4.31,95 \%$ CI 1.29, 14.37). Being born premature ( $<37$ weeks gestation) was significantly decreased the odds of delayed vaccine receipt at 2 months of age (OR 0.15 , 95\% CI 0-0.96). There was likely to be insufficient 
Table 3 Coverage of children fully immunised at date of their enrolment

\begin{tabular}{llll}
\hline Age & Eligible children & $\begin{array}{l}\text { Children fully immunised } \\
\mathrm{n}(\%, 95 \% \mathrm{Cl})\end{array}$ & $\begin{array}{l}\text { Children fully immunised, excluding rotavirus vaccine. } \\
\mathrm{n}(\%, 95 \% \mathrm{Cl})\end{array}$ \\
\hline 7 months $^{\mathrm{a}}$ & $\mathrm{N}$ & $50(47.6,37.9-57.3)$ & $57(54.3,44.6-64.0)$ \\
13 months $^{\mathrm{b}}$ & 105 & $30(35.3,24.9-45.7)$ & $35(41.2,30.5-51.6)$ \\
19 months $^{c}$ & 85 & $12(18.5,8.8-28.2)$ & $14(21.5,11.3-31.8)$ \\
\hline
\end{tabular}

${ }^{\mathrm{a}}$ Fully immunised at 7 months $=3$ doses of each of DTP, hib, polio, PCV, hepB and rotavirus; ${ }^{\mathrm{b}}$ Fully immunised at 13 months $=3$ doses of each of DTP, polio, PCV, hepB and rotavirus, 4 doses of hib, 1 dose of MMR and 1 dose of menC; ${ }^{C}$ Fully immunised at 19 months $=3$ doses of each of DTP, polio, PCV, hepB and rotavirus, 4 doses of hib, 1 dose of MMR, 1 dose of menC, 1 dose of varicella and 1 dose of hepA

power to statistically support other potential associations and multivariate regression was therefore not performed.

\section{Discussion}

We examined immunisation coverage and timeliness in a cohort of urban Indigenous children. According to participants' ACIR records, less than half of the children aged $\geq 7,13$ or 19 -months were up-to-date at enrolment into the cohort study. Delays in vaccine receipt increased as infants aged and parent/guardian reporting of vaccination status was unreliable. Given the higher incidence of vaccine preventable diseases in Indigenous children [3], and the importance of herd immunity, our data provide further support for the need to identify evidence-based strategies to improve timeliness [17] among this population.

Our results are consistent with a Northern Territory (NT) cohort study [9] that reported coverage of the primary series (also at 7-months of age) as 45.2\%; coverage in this NT cohort was lower amongst children living in urban areas compared to remote areas. The authors suggested the reasons for the regional differences were likely related to differences in health service delivery and/or population movement between urban and remote areas. The proportion of timely immunisation of DTP in our cohort also falls within the ranges reported in an analysis of immunisation from 31 low and middle income countries [1] in which the timeliness of DTP was 67\% (11.6-89.3\%) for the first dose and $41 \%(10.8-82.1 \%)$ for the third dose. The proportions of our cohort with delayed receipt of DTP3 (39.9\%) and PCV3 (40.2\%) are comparable to national timeliness data of these vaccines $(38.2 \%$ and $40.5 \%$ for DTP3 and PCV3 respectively) [5], however delayed receipt of MMR at 12 months was higher in our cohort compared to national data ( $53.7 \%$ vs $40.3 \%)$.

Table 4 Proportions of vaccine receipt and timeliness amongst eligible children

\begin{tabular}{|c|c|c|c|c|c|c|c|}
\hline Vaccine & $\begin{array}{l}\text { Eligible children }{ }^{a} \\
\mathrm{~N}(\%)\end{array}$ & $\begin{array}{l}\text { Total not received } \\
\text { N }(\%)\end{array}$ & $\begin{array}{l}\text { Total received } \\
\mathrm{N}(\%)\end{array}$ & $\begin{array}{l}\text { No delay } \\
\mathrm{N}(\%)\end{array}$ & $\begin{array}{l}\text { Early } \\
\mathrm{N}(\%)\end{array}$ & $\begin{array}{l}\text { Delayed } \\
\text { N (\%) }\end{array}$ & $\begin{array}{l}\text { Median number of } \\
\text { weeks delayed } \\
\text { Mdn (IQR) }\end{array}$ \\
\hline PCV 1 (2 months) & $126(90.0)$ & $1(0.8)$ & $125(99.2)$ & $99(79.2)$ & $1(0.8)$ & $25(20.0)$ & $9.1(17.6-1.3)$ \\
\hline PCV 2 (4 months) & $120(85.7)$ & $7(5.8)$ & $113(94.2)$ & $72(63.7)$ & $0(0.0)$ & $41(36.3)$ & $7.4(16.4-3.4)$ \\
\hline PCV 3 (6 months) & $105(75.0)$ & $13(12.4)$ & $92(87.6)$ & $54(58.7)$ & $1(1.1)$ & $37(40.2)$ & $10.4(26.1-5.1)$ \\
\hline DTP, polio \& HepB 1 (2 months) & $126(90.0)$ & $1(0.8)$ & $125(99.2)$ & $98(78.4)$ & $1(0.8)$ & $26(20.8)$ & $9.0(18.0-1.3)$ \\
\hline DTP, polio \& HepB 2 (4 months) & $120(85.7)$ & $7(5.8)$ & $113(94.2)$ & $72(63.7)$ & $0(0.0)$ & $41(36.3)$ & $7.4(16.4-3.4)$ \\
\hline DTP, polio \& HepB 3 (6 months) & $105(75.0)$ & $14(13.3)$ & $91(86.7)$ & $54(59.3)$ & $1(1.1)$ & $36(39.6)$ & $10.5(24.9-3.9)$ \\
\hline Hib 1 (2 months) & $126(90.0)$ & $1(0.8)$ & $125(99.2)$ & $98(78.4)$ & $1(0.8)$ & $26(20.8)$ & $9.0(18.0-1.3)$ \\
\hline Hib 2 (4 months) & $120(85.7)$ & $7(5.8)$ & $113(94.2)$ & $72(63.7)$ & $0(0.0)$ & $41(36.3)$ & $7.4(16.4-3.4)$ \\
\hline Hib 3 (6 months) & $105(75.0)$ & $14(13.3)$ & $91(86.7)$ & $54(59.3)$ & $1(1.1)$ & $36(39.6)$ & $10.5(24.9-3.9)$ \\
\hline Rota 1 (2 months) & $126(90.0)$ & $19(15.1)$ & $107(84.9)$ & $96(89.7)$ & $1(0.9)$ & $10(9.3)$ & $1.4(12.7-1.0)$ \\
\hline Rota 2 (4 months) & $120(85.7)$ & $32(26.7)$ & $88(73.3)$ & $70(79.5)$ & $0(0.0)$ & $18(20.5)$ & $2.9(5.9-1.0)$ \\
\hline Rota 3 (6 months) & $105(75.0)$ & $45(42.9)$ & $60(57.1)$ & $49(81.7)$ & $1(1.7)$ & $10(16.7)$ & $1.4(2.3-0.7)$ \\
\hline MMR (12 months) & $85(60.7)$ & $3(3.5)$ & $82(96.5)$ & $38(46.3)$ & $0(0.0)$ & $44(53.7)$ & $7.4(15.9-3.4)$ \\
\hline MenC (12 months) & $85(60.7)$ & $4(4.7)$ & $81(95.3)$ & $38(44.7)$ & $0(0.0)$ & $43(50.6)$ & $7.3(15.0-3.4)$ \\
\hline Hib 4 (12 months) & $85(60.7)$ & $13(15.3)$ & $72(84.7)$ & $36(50.0)$ & $0(0.0)$ & $36(50.0)$ & $5.8(10.7-3.1)$ \\
\hline Varicella (18 months) & $65(46.4)$ & $6(9.2)$ & $59(90.8)$ & $28(47.5)$ & $3(5.1)$ & $28(47.5)$ & $12.8(42.3-2.9)$ \\
\hline HepA (18 months) & $65(46.4)$ & $15(23.1)$ & $50(76.9)$ & $13(26.0)$ & $1(2.0)$ & $36(72.0)$ & $19.2(37.7-4.1)$ \\
\hline
\end{tabular}

${ }^{a}$ Eligibility for 2 month vaccines = child $\geq 3$ months of age at enrolment, eligibility for 4 month vaccines $=$ child $\geq 5$ months of age at enrolment, eligibility for 6 month vaccines $=$ child $\geq 7$ months of age at enrolment, eligibility for 12 month vaccines $=$ child $\geq 13$ months of age at enrolment, eligibility for 18 month vaccines $=$ child $\geq 19$ months of age at enrolment 


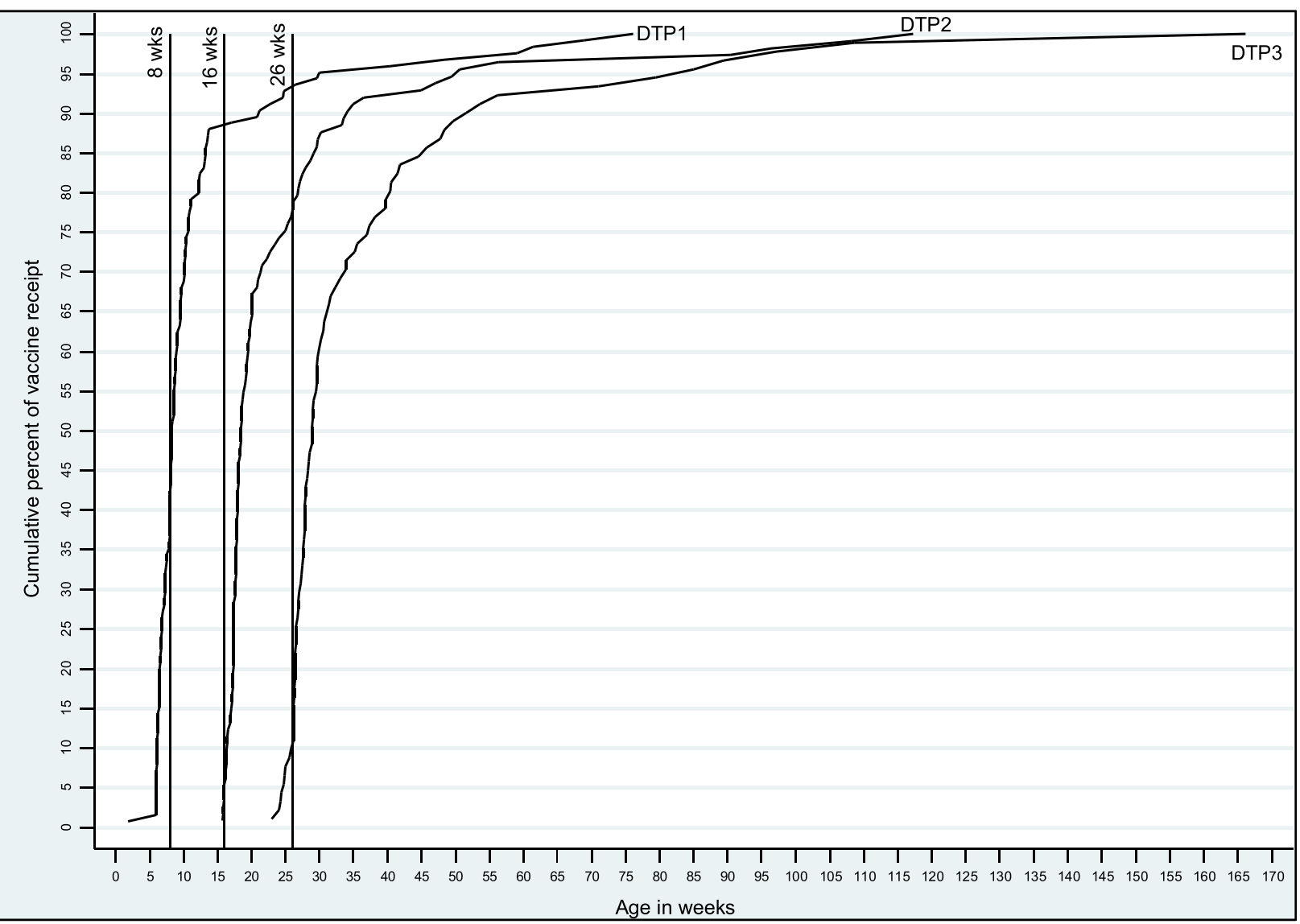

Fig. 1 Cumulative percent of receipt of DTP due at 2, 4,6 months among eligible children

We also found that immunisation coverage and timeliness decreased as children got older; the proportion of delayed receipt increased by 19 percentage points between the first and third dose of DTP. This is consistent with findings from a study of an urban NSW Indigenous cohort [10], the NT data [9] and international data [1].

Non-receipt was highest for rotavirus vaccines, likely due to the upper age restrictions of administering rotavirus vaccines, and for the HepA vaccine at 18-months of age. We also identified that rotavirus vaccines were received after the recommended upper age limit among some children, potentially increasing the infant's risk of intussusception [18]. Hull et al. [19] predicted potential impacts of these strict age-limits which included lower coverage of other vaccinations due to non-vaccination of late presenters, and non-adherence to age cut-offs. Our results support both of these predictions. Greater attention needs to be given to appropriate and timely administration of rotavirus vaccinations and providers may need to be reminded of the importance of adhering to the age limits of vaccine receipt.

Previous research suggests Indigenous-specific vaccines have lower levels of uptake in their target population than universally-recommended vaccines [6]. This was evident in our study population with a greater proportion of children receiving the universally recommended varicella vaccine at 18-months, compared to the Indigenousspecific HepA vaccine. Proportions of receipt in this cohort also differed between the three vaccines due at 12 months. Fragmented vaccine administration has been identified in previous studies amongst both Indigenous and non-Indigenous children. Ferson et al., found that among a cohort of non-Indigenous children, 9.2\% of fully-immunised children had received vaccines due at the same time on separate occasions [20]. Similarly, O'Grady et al. [9] found differences in coverage of 7vPCV and DTP over the time period in which the $7 \mathrm{vPCV}$ was introduced in Australia. Administration of vaccines on separate occasions is reported to be a significant predictor of vaccination delay [21]. This could have contributed to the high rates of non-receipt and/or delayed receipt in our study. Despite national recommendations approving simultaneous administration of multiple vaccines, research suggests fragmented vaccine administration is often related to the advice and practices of immunisation providers $[20,21]$. Further research needs to be conducted to 
Table 5 Characteristics associated with delayed receipt of DTP at 2, 4 and 6 months of age

\begin{tabular}{|c|c|c|c|c|c|c|c|c|c|c|c|c|}
\hline \multirow[t]{2}{*}{ Characteristic } & \multicolumn{3}{|l|}{2 months } & \multicolumn{3}{|l|}{4 months } & \multicolumn{3}{|l|}{6 months } & \multicolumn{3}{|l|}{ Any delayed } \\
\hline & $\begin{array}{l}\text { Delayed: } \mathrm{n} / \mathrm{N} \\
\text { (\%) }\end{array}$ & OR $(95 \% \mathrm{Cl})$ & $p$-value & $\begin{array}{l}\text { Delayed: } \mathrm{n} / \mathrm{N} \\
(\%)\end{array}$ & OR $(95 \% \mathrm{Cl})$ & $p$-value & $\begin{array}{l}\text { Delayed: } \mathrm{n} / \mathrm{N} \\
(\%)\end{array}$ & OR $(95 \% \mathrm{Cl})$ & $p$-value & $\begin{array}{l}\text { Delayed: } \mathrm{n} / \mathrm{N} \\
(\%)\end{array}$ & OR $(95 \% \mathrm{Cl})$ & $p$-value \\
\hline \multicolumn{13}{|l|}{ Sex } \\
\hline Male & $16 / 64(25.0)$ & & & 29/61 (47.5) & & & 28/52 (53.8) & & & $36 / 65(55.4)$ & & \\
\hline Female & $11 / 62(17.7)$ & $0.65(0.27-1.53)$ & 0.32 & 19/59 (32.2) & $0.52(0.25-1.10)$ & 0.09 & $22 / 53(41.5)$ & $0.61(0.28-1.32)$ & 0.21 & $25 / 61(41.0)$ & $0.56(0.28-1.13)$ & 0.12 \\
\hline \multicolumn{13}{|l|}{ Care type } \\
\hline Both parents & 17/69 (24.6) & & & $28 / 67(41.8)$ & & & $30 / 59(50.8)$ & & & $33 / 68(48.5)$ & & \\
\hline Single parent & 9/48 (18.8) & $0.71(0.25-1.89)$ & 0.60 & 19/44 (43.2) & $1.06(0.46-2.44)$ & 1.00 & 18/38 (47.4) & $0.87(0.35-2.13)$ & 0.90 & $27 / 50(54.0)$ & $1.24(0.56-2.76)$ & 0.69 \\
\hline Other $^{\mathrm{a}}$ & $1 / 8(12.5)$ & $0.44(0.01-3.85)$ & 0.79 & $1 / 8(12.5)$ & $0.20(0.00-1.72)$ & 0.21 & 2/7 (28.6) & $0.39(0.03-2.63)$ & 0.48 & 1/7 (14.3) & $0.18(0.00-1.61)$ & 0.18 \\
\hline \multicolumn{13}{|l|}{ Primary Carer } \\
\hline Mother & 25/103 (24.3) & & & $42 / 98(42.9)$ & & & $42 / 86(48.8)$ & & & $52 / 104(50.0)$ & & \\
\hline Other ${ }^{b}$ & 2/16 (12.5) & $0.45(0.05-2.17)$ & 0.48 & 5/15 (33.3) & $0.67(0.21-2.10)$ & 0.49 & $5 / 12(41.7)$ & $0.75(0.22-2.54)$ & 0.64 & 5/15 (33.3) & $0.50(0.16-1.56)$ & 0.23 \\
\hline \multicolumn{13}{|l|}{ Child care } \\
\hline No & 22/90 (24.4) & & & $35 / 84(41.7)$ & & & $34 / 71(47.9)$ & & & 43/90 (47.8) & & \\
\hline Yes & $5 / 35(14.3)$ & $0.52(0.18-1.49)$ & 0.22 & 13/35 (37.1) & $0.83(0.37-1.86)$ & 0.65 & 15/33 (45.5) & $0.91(0.40-2.08)$ & 0.82 & 17/35 (48.6) & $1.03(0.47-2.25)$ & 0.94 \\
\hline \multicolumn{13}{|l|}{ Education level of mother } \\
\hline Did not finish high school & 10/51 (19.6) & & & 19/49 (38.8) & & & 23/45 (51.1) & & & $27 / 51(52.9)$ & & \\
\hline High school & 13/56 (23.2) & $1.24(0.44-3.53)$ & 0.83 & 21/53 (39.6) & $1.04(0.47-2.30)$ & 0.93 & $18 / 45(40.0)$ & $0.64(0.28-1.47)$ & 0.29 & $24 / 56(42.9)$ & $0.67(0.31-1.43)$ & 0.30 \\
\hline Post-school qualification ${ }^{c}$ & $3 / 15(20.0)$ & $1.02(0.16-4.92)$ & 1.00 & $6 / 14(42.9)$ & $1.18(0.36-3.95)$ & 0.78 & $6 / 12(50.0)$ & $0.96(0.27-3.42)$ & 0.95 & $7 / 15(46.7)$ & $0.78(0.25-2.47)$ & 0.67 \\
\hline \multicolumn{13}{|l|}{ Education level of father } \\
\hline Did not finish high school & 14/57 (24.6) & & & 21/54 (38.9) & & & $25 / 48(52.1)$ & & & $30 / 56(53.6)$ & & \\
\hline High school & $8 / 31(25.8)$ & $1.07(0.34-3.22)$ & 1.00 & $14 / 30(46.7)$ & $1.37(0.50-3.72)$ & 0.64 & $12 / 26(46.2)$ & $0.79(0.30-2.05)$ & 0.63 & $15 / 31(48.4)$ & $0.81(0.31-2.14)$ & 0.81 \\
\hline Post-school qualification ${ }^{c}$ & 1/14 (7.14) & $0.24(0.01-1.89)$ & 0.28 & 4/13 (30.8) & $0.70(0.14-2.93)$ & 0.84 & $5 / 10(50.0)$ & $0.92(0.24-3.59)$ & 0.91 & 4/13 (30.8) & $0.39(0.08-1.60)$ & 0.23 \\
\hline \multicolumn{13}{|l|}{ Employment status of mother } \\
\hline Employed $^{d}$ & $1 / 15(6.7)$ & & & $3 / 14(21.4)$ & & & $3 / 12(25.0)$ & & & 2/14 (14.3) & & \\
\hline Unemployed & 26/109 (23.9) & $4.35(0.60-192.46)$ & 0.23 & $45 / 104(43.3)$ & $2.77(0.68-16.40)$ & 0.20 & $46 / 92(50.0)$ & $2.97(0.68-18.14)$ & 0.18 & $58 / 110(52.7)$ & $6.60(1.37-63.51)$ & 0.01 \\
\hline \multicolumn{13}{|l|}{ Employment status of father } \\
\hline Employed $^{d}$ & $11 / 53(20.8)$ & & & 19/49(38.8) & & & 19/43 (44.2) & & & $22 / 52(42.3)$ & $1.74(0.79-3.80)$ & 0.17 \\
\hline Unemployed & 13/51 (25.5) & $1.31(0.52-3.26)$ & 0.57 & $22 / 49(44.9)$ & $1.29(0.58-2.88)$ & 0.54 & 24/43 (55.8) & $1.60(0.68-3.74)$ & 0.28 & $28 / 50(56.0)$ & $0.73(0.42-1.27)$ & 0.27 \\
\hline \multicolumn{13}{|c|}{ Number of other children in household } \\
\hline 0 & $3 / 26(11.5)$ & & & $5 / 23(21.7)$ & & & $5 / 19(26.3)$ & & & 5/24 (20.8) & & \\
\hline $1-2$ & $17 / 68(25.0)$ & $2.53(0.64-14.81)$ & 0.25 & $30 / 66(45.5)$ & $3.00(1.00-9.04)$ & 0.05 & $31 / 59(52.5)$ & $3.10(0.99-9.71)$ & 0.05 & $37 / 68(54.4)$ & $4.54(1.52-13.55)$ & 0.01 \\
\hline $3+$ & $7 / 30(23.3)$ & $2.30(0.45-15.49)$ & 0.43 & $13 / 29(44.8)$ & $2.93(0.85-10.02)$ & 0.09 & $12 / 25(48.0)$ & $2.58(0.71-9.37)$ & 0.15 & $17 / 32(53.1)$ & $4.31(1.29-14.37$ & 0.02 \\
\hline
\end{tabular}


Table 5 Characteristics associated with delayed receipt of DTP at 2, 4 and 6 months of age (Continued)

\begin{tabular}{|c|c|c|c|c|c|c|c|c|c|c|c|c|}
\hline \multicolumn{13}{|l|}{ Income level } \\
\hline$<\$ 26,000$ & $8 / 42(19.0)$ & & & $19 / 40(47.5)$ & & & 20/35 (37.7) & & & 28/44 (63.6) & & \\
\hline$\$ 26,000-\leq \$ 52,000$ & 15/49 (30.6) & $1.86(0.64-5.79)$ & 0.31 & 20/47 (42.6) & $0.82(0.32-2.08)$ & 0.81 & $18 / 40(45.0)$ & $0.62(0.22-1.68)$ & 0.41 & 22/49 (44.9) & $0.47(0.19-1.16)$ & 0.11 \\
\hline$\$ 52,000-\leq \$ 78,000$ & 3/21 (14.3) & $0.71(0.11-3.46)$ & 0.93 & 6/19 (31.6) & $0.52(0.13-1.82)$ & 0.38 & 8/18 (44.4) & $0.61(0.16-2.18$ & 0.56 & 7/19 (36.8) & $0.34(0.09-1.16)$ & 0.09 \\
\hline$>\$ 78,000$ & 1/9 (11.1) & $0.54(0.01-5.13)$ & 0.99 & 2/9 (22.2) & $0.32(0.03-1.98)$ & 0.31 & 2/7 (28.6) & $0.31(0.03-2.21)$ & 0.33 & 2/9 (22.2) & $0.17(0.02-1.03)$ & 0.06 \\
\hline \multicolumn{13}{|l|}{ Father's age at birth of child } \\
\hline$<20$ years & 2/7 (28.6) & & & 3/7 (42.9) & & & 4/7 (57.1) & & & 5/7 (71.4) & & \\
\hline 20-29 years & 16/76 (21.1) & $0.67(0.10-7.66)$ & 0.95 & 28/71 (39.4) & $0.87(0.14-6.39)$ & 1.00 & $32 / 64(50.0)$ & $0.75(0.10-4.84)$ & 1.00 & 37/76 (48.7) & $0.38(0.03-2.52)$ & 0.45 \\
\hline$\geq 30$ years & $8 / 38(21.1)$ & $0.67(0.09-8.32)$ & 0.99 & 16/37 (43.2) & $1.01(0.15-7.93)$ & 1.00 & $12 / 29(41.4)$ & $0.54(0.07-3.84)$ & 0.74 & 17/38 (44.7) & $0.33(0.03-2.34)$ & 0.38 \\
\hline \multicolumn{13}{|c|}{ Mother's age at birth of child } \\
\hline$<20$ years & $6 / 28(21.4)$ & & & $11 / 27(40.7)$ & & & $14 / 26(53.8)$ & & & 14/28 (50.0) & & \\
\hline 20-29 years & 16/67 (23.9) & $1.15(0.36-4.08)$ & 1.00 & 25/63 (39.7) & $0.96(0.35-2.69)$ & 1.00 & 27/55 (49.1) & $0.83(0.29-2.33)$ & 0.87 & $34 / 67(50.7)$ & $1.03(0.43-2.49)$ & 0.95 \\
\hline$\geq 30$ years & 4/29 (13.8) & $0.59(0.11-2.88)$ & 0.68 & 11/28 (39.3) & $0.94(0.28-3.17)$ & 1.00 & $7 / 22(31.8)$ & $0.41(0.10-1.51)$ & 0.21 & 11/29 (37.9) & $0.61(0.21-1.75)$ & 0.36 \\
\hline \multicolumn{13}{|l|}{ Gestational age } \\
\hline$\geq 37$ weeks gestation & 26/108 (24.1) & & & 44/103 (42.7) & & & 44/91 (48.4) & & & $55 / 108(50.9)$ & & \\
\hline$<37$ weeks gestation & 0/15 (0.0) & $0.15(0-0.96)$ & 0.04 & 3/14 (21.4) & $0.37(0.06-1.51)$ & 0.21 & 4/11 (36.4) & $0.61(0.12-2.61)$ & 0.67 & 4/15 (26.7) & $0.35(0.08-1.29)$ & 0.13 \\
\hline \multicolumn{13}{|l|}{ Birthweight } \\
\hline$\geq 2500$ grams & 25/103 (24.3) & & & 42/98 (42.9) & & & 43/87 (49.4) & & & 53/103 (51.5) & & \\
\hline$<2500$ grams & 1/20 (5.0) & $0.17(0.00-1.15)$ & 0.08 & 5/19 (26.3) & $0.48(0.12-1.55)$ & 0.27 & 5/15 (33.3) & $0.51(0.13-1.82)$ & 0.38 & 6/20 (30.0) & $0.40(0.14-1.13)$ & 0.09 \\
\hline
\end{tabular}

${ }^{a}$ Other $=$ shared, other relative, other non-family member; ${ }^{b}$ Other $=$ Father, Mother and Father, Grandparent, Grandparent and Father, Other non-family; ${ }^{c}$ Post-school qualification $=$ Certificate, Diploma, Bachelor Degree; ${ }^{\mathrm{d}}$ Employed = Full Time, Part Time, Casual 
determine the extent to which this phenomenon currently occurs in Australia and to understand provider's intentions if and when making these recommendations.

We found that parental report of their child's immunisation status over-estimated the proportion of children up-to-date. Thus, in this community, and potentially other similar communities, immunisation status should be confirmed by another source. Possible reasons as to why parents may believe their children are up-to-date could include a lack of parental understanding of what vaccines are required, a lack of personal vaccination records and/or communication issues between parents and health providers.

Despite the significant body of evidence indicating the need to improve timeliness among urban Australian Indigenous children, there is a lack of studies evaluating interventions to do this. One Australian study found that the distribution of personalised calendars to parents through health clinics was an effective and culturally appropriate way to improve timeliness of the primary series [22]. Identifying risk factors associated with nontimeliness may inform appropriate intervention points. We found that having other children in the household and a mother who was unemployed were potential predictors of delayed receipt of DTP at 2, 4 and/or 6-months, whereas prematurity was associated with a decreased odds of delayed vaccine receipt. . Living in a household with multiple children has previously been identified as a predictor of vaccination delay in Australia and internationally $[1,21,23,24]$, suggesting additional support needs to be provided for these families. While it could be presumed that being an unemployed mother may allow for greater time to have children vaccinated, unemployed mothers may be more likely to lack other resources such as finances, transport and social support. Other studies $[21,23]$ have identified single-parent households and low levels of parental education as predictors of delayed vaccine receipt, however we were unable to demonstrate these associations with the available data.

The main strength of this study is the use of ACIR records as the primary measure of a child's immunisation status. ACIR records were retrievable for $97 \%$ of children we recruited. The allowance of 3 months lag between when the last vaccine in the cohort was due and the data of retrieval of ACIR records reduced the likelihood that incomplete immunisation records were due to reporting or processes delays. We did not employ the third-dose assumption that is routinely used to determine national immunisation coverage in this study. While this has been previously reported as a valid assumption $[16,25]$, these studies were conducted over a decade ago making their current applicability questionable, particularly given changes over time from a paper-based submission system to an electronic one. We could not validate the third dose assumption with personal health or clinic records as many of the study children received health care and vaccines at clinics other than our study site, particularly the one third $(44 / 140)$ that were born prior to the opening of the clinic in July 2011. By using the 3rd dose assumption our analyses would have included an additional 21 vaccines administered between 8 kids. Hull and McIntyre [25] calculated that use of the third dose assumption increased the proportion of children fully immunised by $11-12 \%$. While this would have raised the proportion of children fully immunised in our population to $59.6,47.3$ and $30.5 \%$ at 7,13 and 19 months respectively, these levels remain noticeably below national levels.

Our analyses of potential predictors of timeliness and coverage were limited by the sample size and that child characteristics were collected at enrolment, not at the time vaccines were administered. It is possible that several of these factors would have changed between vaccine receipt and enrolment; however our results are consistent with other studies $[1,26]$. Nevertheless comprehensive prospective studies are needed to confirm predictors of timely immunisation amenable to intervention. Finally, due to the retrospective nature of this study and the use of ACIR records, we were unable to assess to what extent early or delayed vaccine receipt was an intentional decision made by the immunisation provider and/or family.

\section{Conclusions}

Immunisation coverage and timeliness in this population during the first 18-months of life was inadequate, placing children at increased risk of acquiring vaccine preventable infections during infancy and childhood. High quality trials, conducted in several settings to account for the diversity of Australian Indigenous communities are urgently needed to identify culturally appropriate, effective and sustainable strategies to improve immunisation targets in children.

This will also assist in highlighting subpopulations most in need of improvement and in monitoring change over time. Our data suggest that families with multiple children, low income or when the mother is unemployed should be specifically targeted for interventions such as intensive follow-up, home visiting and other support mechanisms. Further research needs to be conducted into the extent and cause of fragmented vaccine administration, as well as predictors of delayed receipt in a larger study.

\section{Abbreviations}

7VPCV: 7-valent pneumococcal conjugate vaccine; ACIR: Australian Childhood Immunisation Register; ARI: Acute respiratory illness; DTP: Diphtheria-tetanuspertussis; HepA: Hepatitis A; HepB: Hepatitis B; Hib: Haemophilus influenza type b; MenC: Meningococcal C; MMR: Measles-mumps-rubella; NT: Northern Territory; PCV: Pneumococcal conjugate vaccine; Rota: Rotavirus 


\section{Acknowledgements}

This study would not have been possible without the cooperation and collaboration provided by the staff of Murri Medical, Caboolture; as well as the participation of the parents and carers of the study children. We also acknowledge Daniel Arnold for his assistance with data management and extraction

\section{Funding}

This study was funded by a Queensland Children's Medical Research Institute Project Grant. YLT was funded by a Queensland University of Technology Vacation Research Experience Scheme grant. KH is funded by a QUT Australian Postgraduate Award and a NHMRC Centre for Research Excellence in Lung Health for Aboriginal and Torres Strait Islander children Top-Up Scholarship. KFO is supported by a NHMRC Career Development Fellowship (1045157) and Queensland Government Smart Futures Fellowship. ABC is supported by NHMRC Practitioner Fellowship (1058213).

\section{Availability of data and materials}

Study data and materials may be made available on request with appropriate human research ethics committee approval and with the consent of the participating community as required by Australian criteria for research with Indigenous communities.

\section{Authors' contributions}

YLT analysed and interpreted the data and drafted the all versions of the manuscript. AC conceptualised and designed the overall study and revised the first and final versions of the manuscript. JA conceptualised, designed and implemented the overall study. $\mathrm{KH}$ is a $\mathrm{PhD}$ on the overall study and recruited all participants and acquired the data. KOF is chief investigator on the overall study, assisted with data analysis and interoperation and revised all versions of the manuscript. All authors approved the final version of the manuscript.

\section{Competing interests}

$Y L T, K H, K F O$ and $A B C$ have no relevant disclosures. JA is the director of the participating health clinic. The authors declare that they have no competing interests.

\section{Consent for publication}

Not applicable.

\section{Ethics approval and consent to participate}

Ethical approval was obtained from the Queensland Children's Health Services (HREC/12/QRCH/169) and the Queensland University of Technology (1300000741) Human Research Ethics Committees. Written consent was obtained from the parent(s)/guardian(s) of the study participant before study entry.

\section{Author details}

${ }^{1}$ Institute of Health \& Biomedical Innovation, Queensland University of Technology, Centre for Children's Health Research, South Brisbane, QLD, Australia. ${ }^{2}$ Menzies School of Health Research, Charles Darwin University, Tiwi, NT, Australia. ${ }^{3}$ Respiratory Department, Lady Cilento Children's Hospital, South Brisbane, QLD, Australia. ${ }^{4}$ Murri Health Group, Caboolture, QLD, Australia.

\section{Received: 31 May 2016 Accepted: 8 November 2016} Published online: 14 November 2016

\section{References}

1. Akmatov MK, Mikolajczyk RT. Timeliness of childhood vaccinations in 31 low and middle-income countries. J Epidemiol Community Health. 2012; 66(7):e14. doi:10.1136/jech.2010.124651.

2. Peltola H. Worldwide Haemophilus influenzae type b disease at the beginning of the 21st century: global analysis of the disease burden 25 years after the use of the polysaccharide vaccine and a decade after the advent of conjugates. Clin Microbiol Rev. 2000;13(2):302-17. doi:10.1128/ CMR.13.2.302-317.2000.
3. Naidu L, Chiu C, Habig A, Lowbridge C, Jayasinghe S, Wang H, et al. Vaccine preventable diseases and vaccination coverage in Aboriginal and Torres Strait Islander people, Australia 2006-2010. Commun Dis Intell. 2013; 37(Suppl):S1-S95.

4. Kolos V, Menzies R, McIntyre P. Higher pertussis hospitalization rates in indigenous Australian infants, and delayed vaccination. Vaccine. 2007;25(4):588-90. doi:10.1016/j.vaccine.2006.08.022.

5. Hull BP, Dey A, Beard FH, Menzies RI, Brotherton JM, Mclntyre PB. Immunisation coverage annual report, 2013. Commun Dis Intell. 2016;40(1):24.

6. Menzies R, Andrews R. Immunisation issues for Indigenous Australian children. J Paediatr Child Health. 2014;50(10):E21-E5. doi:10.1111/j.14401754.2011.02079.x.

7. Hull BP, Mclntyre PB. Timeliness of childhood immunisation in Australia. Vaccine. 2006;24(20):4403-8. doi:10.1016/j.vaccine.2006.02.049.

8. Fadnes LT, Nankabirwa V, Sommerfelt H, Tylleskär T, Tumwine JK, Engebretsen IMS, et al. Is vaccination coverage a good indicator of ageappropriate vaccination? A prospective study from Uganda. Vaccine. 2011;29(19):3564-70. doi:10.1016/j.vaccine.2011.02.093.

9. O'Grady K-A, Krause V, Andrews R. Immunisation coverage in Australian indigenous children: time to move the goal posts. Vaccine. 2009;27(2):307-12. doi:10.1016/j.vaccine.2008.09.096.

10. Harris MF, Webster V, Jalaludin B, Jackson Pulver LR, Comino EJ. Immunisation coverage among a birth cohort of Aboriginal infants in an urban community. J Paediatr Child Health. 2014;50(4):306-13. doi:10.1111/jpc.12482.

11. Queensland Treasury and Trade-Office of Economic and Statistical Research. Census 2011: Aboriginal and Torres Strait Islander Population in Queensland 2nd ed. Brisbane: Queensland Treasury and Trade; 2013. http://www.qgso.qld.gov.au/ products/reports/atsi-pop-qld-c11/atsi-pop-qld-c11.pdf. Accessed 3 Sept 2015.

12. Hall KK, Chang AB, Sloots TP, Anderson J, Kemp A, Hammill J, et al. The respiratory health of urban indigenous children aged less than 5 years: study protocol for a prospective cohort study. BMC Pediatr. 2015;15:56. doi:10.1186/s12887-015-0375-y.

13. National Health and Medical Research Council. Values and Ethics: Guidelines for Ethical Conduct in Aboriginal and Torres Strait Islander Health Research. 2003. Canberra: Commonwealth of Australia; 2003. https://www.nhmrc.gov.au/files_nhmrc/publications/attachments/e52. pdf. Accessed 21 Sept 2016.

14. Australian Institute of Health and Welfare. Indigenous statistics: quality and availability. 2016. http//mww.aihw.gov.au/indigenous-statistics-quality-availability/. Accessed 21 Sept 2016.

15. SA Department of Health, Australian Government Department of Health and Ageing. Immunisation schedules. South Australia: Government of South Australia; 2015. https://immunisationcalculator.sahealth.sa.gov.au/ ImmSchedules.aspx. Accessed 14 Jan 2015.

16. Mclntyre $P B$, Hull BP, Lawrence GL, Maclntyre CR. Estimating immunisation coverage: is the 'third dose assumption' still valid? Commun Dis Intell. 2003;27(3):357-61. doi:10.1111/j.1467-842X.2000.tb00717.x.

17. Royle J, Lambert SB. Fifty years of immunisation in Australia (1964-2014): The increasing opportunity to prevent diseases. J Paediatr Child Health. 2015;51(1):16-20l. doi:10.1111/jpc.12796.

18. Carlin JB, Macartney KK, Lee KJ, Quinn HE, Buttery J, Lopert R, et al. Intussusception risk and disease prevention associated with rotavirus vaccines in Australia's national immunization program. Clin Infect Dis. 2013;57(10):1427-34. doi:10.3410/f.718078171.793488338.

19. Hull BP, Menzies R, Macartney K, McIntyre PB. Impact of the introduction of rotavirus vaccine on the timeliness of other scheduled vaccines: the Australian experience. Vaccine. 2013;31(15):1964-9. doi:10.1016/j.vaccine. 2013.02.007.

20. MacArtney-Bourne F, McKenzie KA, Ferson MJ. Fragmentation of scheduled visits and missed doses among infants receiving multiple injected vaccines. Aust N Z J Public Health. 1997;21(7):735-8. doi:10.1111/j.1467-842X.1997. tb01789.x.

21. Richards A, Sheridan J. Reasons for delayed compliance with the childhood vaccination schedule and some failings of computerised vaccination registers. Aust N Z J Public Health. 1999;23(3):315-7. doi:10.1111/j.1467-842X. 1999.tb01263.x.

22. Abbott P, Menzies R, Davison J, Moore L, Wang H. Improving immunisation timeliness in Aboriginal children through personalised calendars. BMC Public Health. 2013;13(1):598. doi:10.1186/1471-2458-13-598.

23. Dombkowski KJ, Lantz PM, Freed GL. Risk Factors for Delay in AgeAppropriate Vaccination. Public Health Rep. 2004;119(2):144. 
24. Jeong YW, Park BH, Kim KH, Han YR, Go UY, Choi WS, et al. Timeliness of MMR vaccination and barriers to vaccination in preschool children. Epidemiol Infect. 2011;139(2):247-56. doi:10.1017/S0950268810000889.

25. Hull BP, McIntyre PB. Immunisation coverage reporting through the Australian Childhood Immunisation Register - an evaluation of the thirddose assumption. Aust N Z J Public Health. 2000; 24(1):17-21; doi: 10.1111/j. 1467-842X.2000.tb00717.x27.

26. Hu Y, Chen Y, Guo J, Tang X, Shen L. Completeness and timeliness of vaccination and determinants for low and late uptake among young children in eastern China. Hum Vaccin Immunother. 2014;10(5):1408-15. doi:10.4161/hv.28054.

27. Australian Bureau of Statistics 2012, Census of Population and Housing Aboriginal and Torres Strait Islander Peoples (Indigenous) Profile 2011, 'Table 103: Age by Indigenous Status by Sex', data cube: Excel spreadsheet, cat. no. 2002.0. http://www.censusdata.abs.gov.au/census_services/ getproduct/census/2011/communityprofile/0?opendocument\&navpos=220. Accessed 3 May 2016.

28. Australian Bureau of Statistics 2012, Census of Population and Housing Characteristics of Aboriginal and Torres Strait Islander Australians 2011, Table 3.1: Household Composition, by household and family type', data cube: Excel spreadsheet, cat. no. 2076.0. http://www.abs.gov.au/AUSSTATS/ abs@.nsf/DetailsPage/2076.02011?OpenDocument. Accessed 3 May 2016.

29. Australian Bureau of Statistics 2010, The Health and Welfare of Australia's Aboriginal and Torres Strait Islander Peoples 2010: Access to health and community services, Table 2.1 Use of childcare, Aboriginal and Torres Strait Islander Children 2008', data cube: Excel spreadsheet, cat. no. 4704.0. http://www.abs.gov.au/AUSSTATS/abs@.nsf/DetailsPage/4704.00ct\%202010?Open Document. Accessed 3 May 2016

30. Australian Bureau of Statistics 2014, Australian Social Trends - Exploring the gap in labour market outcomes for Aboriginal and Torres Strait Islander Peoples, cat. no. 4102.0. http://www.abs.gov.au/ausstats/abs@.nsf/Lookup/ 4102.0main+features72014. Accessed 3 May 2016.

31. Australian Bureau of Statistics 2012, Census of Population and Housing Characteristics of Aboriginal and Torres Strait Islander Australians 2011 Table 13.2: Equivalised Weekly Household Income, by Indigenous status', data cube: Excel spreadsheet, cat. no. 2076.0. http://www.abs.gov.au/ AUSSTATS/abs@.nsf/DetailsPage/2076.02011?OpenDocument. Accessed 3 May 2016.

32. Australian Bureau of Statistics 2015, Births, Australia, 2014, 'Table 10.9 Multiple births, Australia- 2004 to 2014', data cube: Excel spreadsheet, cat no. 3301.0. http://www.abs.gov.au/AUSSTATS/abs@.nsf/DetailsPage/3301. 02014?OpenDocument. Accessed 3 May 2016

33. Australian Bureau of Statistics 2015, Births, Australia, 2014, 'Table 11.8 Births of Aboriginal and Torres Strait Islander peoples, Summary - Australia- 2009 to 2014', data cube: Excel spreadsheet, cat no. 3301.0. http://www.abs.gov. au/AUSSTATS/abs@.nsf/DetailsPage/3301.02014?OpenDocument. Accessed 03 May 2016.

\section{Submit your next manuscript to BioMed Central and we will help you at every step:}

- We accept pre-submission inquiries

- Our selector tool helps you to find the most relevant journal

- We provide round the clock customer support

- Convenient online submission

- Thorough peer review

- Inclusion in PubMed and all major indexing services

- Maximum visibility for your research

Submit your manuscript at www.biomedcentral.com/submit

CBiomed Central 